\title{
The assessment of vertebral fractures in elderly women with recent hip fractures: the BREAK Study
}

\author{
S. Gonnelli • C. Caffarelli • S. Maggi • S. Rossi • \\ P. Siviero • G. Gandolini • C. Cisari • M. Rossini • \\ G. Iolascon • G. Letizia Mauro • G. Crepaldi • R. Nuti • \\ BREAK Study Group
}

Received: 17 April 2012 / Accepted: 2 August 2012 / Published online: 22 August 2012

(C) International Osteoporosis Foundation and National Osteoporosis Foundation 2012

\begin{abstract}
Summary This study aimed to evaluate the prevalence of vertebral fractures in elderly women with a recent hip fracture. The burden of vertebral fractures expressed by the Spinal Deformity Index (SDI) is more strictly associated with the trochanteric than the cervical localization of hip fracture and may influence short-term functional outcomes.

Introduction This study aimed to determine the prevalence and severity of vertebral fractures in elderly women with recent hip fracture and to assess whether the burden of vertebral fractures may be differently associated with trochanteric hip fractures with respect to cervical hip fractures.

Methods We studied 689 Italian women aged 60 years or over with a recent low trauma hip fracture and for whom an adequate X-ray evaluation of spine was available. All radiographs were examined centrally for the presence of any vertebral deformities and radiological morphometry was
\end{abstract}

\footnotetext{
S. Gonnelli $(\bowtie) \cdot$ C. Caffarelli $\cdot$ R. Nuti

Department of Internal Medicine, Endocrine-Metabolic Science and Biochemistry, University of Siena,

Policlinico Le Scotte, Viale Bracci 2,

53100, Siena, Italy

e-mail: gonnelli@unisi.it

S. Maggi $\cdot$ P. Siviero $\cdot$ G. Crepaldi

CNR Aging Branch, University of Padua,

Padua, Italy

\section{S. Rossi}

Research Centre for Health Promotion and Education, Department Physiopathology, Experimental Medicine and Public Health, University of Siena,

Siena, Italy

G. Gandolini

Don Gnocchi Foundation,

Milan, Italy
}

performed. The SDI, which integrates both the number and the severity of fractures, was also calculated.

Results Prevalent vertebral fractures were present in $55.7 \%$ of subjects and 95 women $(13.7 \%)$ had at least one severe fracture. The women with trochanteric hip fracture showed higher SDI and higher prevalence of diabetes with respect to those with cervical hip fracture, $p=0.017$ and $p=0.001$, respectively. SDI, surgical menopause, family history of fragility fracture, and type2 diabetes mellitus were independently associated with the risk of trochanteric hip fracture. Moreover, a higher SDI was associated with a higher percentage of postsurgery complications $(p=0.05)$ and slower recovery $(p<0.05)$. Conclusions Our study suggests that the burden of prevalent vertebral fractures is more strictly associated with the trochanteric than the cervical localisation of hip fracture and that elevated values of SDI negatively influence short term functional outcomes in women with hip fracture.
C. Cisari

General Hospital,

Novara, Italy

M. Rossini

Rheumatology Unit, Department of Medicine,

University of Verona,

Verona, Italy

G. Iolascon

Department of Orthopedics, University of Naples,

Naples, Italy

G. Letizia Mauro

Department of Rehabilitation, University of Palermo,

Palermo, Italy 
Keywords Cervical fracture $\cdot$ Hip fracture $\cdot$ Spinal deformity index $\cdot$ Trochanteric fracture $\cdot$ Vertebral fracture

\section{Introduction}

Osteoporosis is a multifactorial systemic skeletal disease, characterized by low bone mass and microarchitectural deterioration of bone tissue, with a consequent increase in bone fragility and in susceptibility to fracture [1]. Osteoporotic fractures result in increased mortality, many disabilities and high economic cost. Vertebral fractures are the most common osteoporotic fractures, but only about one third of them come to clinical attention [2]. Hip fracture, the most serious complication of osteoporosis, is becoming more frequent due to the progressive aging of the world population and the annual number of hip fractures is expected to reach 4.5 million by $2050[3,4]$.

It is well established that the presence of one low trauma fracture significantly increases the risk of a further fracture [5-8].

In a systematic review carried out by Klotzbuecher et al. [5], women with a single pre-existing vertebral fracture were 4.4 times more likely to have a further vertebral fracture and 2.3 times more likely to have hip fracture than those without. In particular, Ismail et al. [7] in the European Prospective Osteoporosis Study found that prevalent vertebral deformity in women predicted future hip fracture with a risk ratio of 4.5. Moreover, it has been reported that the incidence rate of a subsequent hip fracture for women aged 80 85 years with a vertebral fracture was $6.5 \%$ at 6 months and $4.2 \%$ at 4 years [9].

Some studies reported that the association between vertebral deformity and hip fracture was largely independent of the severity of the vertebral compressions $[10,11]$. Instead, a recent study carried out on a large Finnish population reported that severe vertebral fractures strongly predicted hip fractures, whereas mild to moderate fracture grades and the number of compressed vertebral bodies showed no prediction for hip fracture [12]. Similarly, a recent paper on the OPUS population has reported that moderate/severe vertebral compressions are likely to be true osteoporotic fractures of the spine and predict vertebral fracture risk better than mild compressions [13].

Recently, there has been a growing interest in literature regarding the hypothesis that the two main categories of hip fracture, cervical and trochanteric, may differ in pathophysiological mechanisms and consequently in predisposing factors [14]. Almost 20 years ago, Katowicz et al. reported that, in women with vertebral fracture, the risk of trochanteric hip fracture increased by $2.3(p<$ 0.05 ) and of cervical hip fracture by 1.3 (N.S.) compared with women without vertebral fracture; this indicates that trochanteric fractures may be more strongly associated with spinal osteoporosis than cervical fractures [15].

Moreover, some studies have reported that patients with trochanteric fractures were older, thinner and shorter and with lower bone mineral density (BMD) and quantitative ultrasound values than patients with cervical fractures [16-18]. However, other authors have found no difference in BMD, prevalent vertebral fractures, or risk factors between the patients with cervical fracture and those with trochanteric fracture $[10,19,20]$.

Moreover, Fisher et al. [20] recently showed that elevated PTH levels increased the odds of trochanteric hip fracture, while blunted PTH response to hypovitaminosis D increased the odds of cervical fracture. Nevertheless, literature data on bone metabolism status, comorbidities, and outcomes with regard to hip fracture type in the elderly remain scant and conflicting [16, 21, 22].

The aim of the present study was twofold: firstly, to determine the prevalence and severity of vertebral fractures in a large cohort of Italian women with recent hip fracture; secondly, to assess whether vertebral fractures, comorbidities and other variables may be differently associated with trochanteric hip fractures with respect to cervical hip fractures.

\section{Materials and methods}

A total of 22 Italian centers (Departments of Orthopaedics, Rehabilitation and Geriatrics) located in both academic and nonacademic general hospitals were invited to participate in the Break Study. The general characteristics of the Break study have been reported previously [23]. In each center, between January 2009 and June 2010, experienced clinicians recruited up to 100 consecutive women, aged 60 years or over with a recent low trauma hip fracture. Low trauma fractures were either spontaneous or caused by minimal trauma (trauma equal to or less than a fall from a standing position). The pathological hip fractures due to primary or metastatic bone cancer, multiple myeloma, Paget's disease of bone, or primary hyperparathyroidism were excluded.

The women enrolled were submitted to a standardized interview. The case report included questions related to age, height and weight, lifestyle (smoking habit, alcohol consumption), patient's history (fracture after the age of 50 years, family history of fragility fracture, age and type of menopause), health status (presence of comorbidities, use of specific drugs, and pre-fracture walking ability), and the type of hip fracture. The history of previous fractures was ascertained by self-report, and no additional validation of this information was 
conducted. Moreover, two radiographs of the thoracic and lumbar spine were obtained according to standardized procedures.

At each center, hip fractures were classified by experienced clinicians on preoperative radiographs and surgical reports as cervical fractures (or medial or intracapsular) and trochanteric fractures (or lateral or extracapsular). Specific training was given to all the investigators in order to avoid any discrepancies in classification of hip fracture. The participating centers completed the forms of 1,288 women of whom 1,249 were eligible for the study; however, complete $\mathrm{X}$-ray evaluation of thoracic and lumbar spine was available only for 727 patients who were the object of the present study.

Study protocol was prepared according to Declaration of Helsinki and subsequent integrations.

Written consent was obtained from all participants, and the study was approved by the local Ethical Committee of each center.

\section{Assessment of vertebral fractures}

All radiographs were examined centrally (at Siena) for the presence of any vertebral deformities by two experienced clinicians (G-S and $\mathrm{C}-\mathrm{C}$ ) who were unaware of the patients characteristics. First, a qualitative evaluation was made to exclude vertebral deformity cause other than osteoporotic fractures and poor X-ray films. In cases of divergent opinions, consensus was reached by discussion with a radiologist. Then, the vertebrae were identified and morphometry was performed from the fourth thoracic vertebra (T4) to the fourth lumbar vertebra (L4) by marking six points in each vertebral body, corresponding to the four corners and the midpoints of the endplates. The anterior (Ha), mid-vertebral ( $\mathrm{Hm})$, and posterior $(\mathrm{Hp})$ heights of each vertebra were measured and the three ratios, $\mathrm{Ha} / \mathrm{Hp}, \mathrm{Hm} / \mathrm{Hp}$, and $\mathrm{Hp} / \mathrm{Hp}$-below, were calculated.

The fractures were defined as mild, moderate, or severe based on a height ratio decrease of 20-25\%, 25-40 \%, and over $40 \%$, respectively, according to Genant's graduation [24]. In all patients, we also evaluated the Spinal Deformity Index (SDI). SDI is an assessment tool similar to the Genant semiquantitative (SQ) approach which integrates both the number and the severity of vertebral fractures. SDI is obtained by summing up the vertebral fracture grades along the spine from $\mathrm{T} 4$ to $\mathrm{L} 4$ where SQ0 indicates absence of fracture and SQ1, SQ2, and SQ3 indicate mild, moderate, or severe fracture, respectively $[25,26]$. Therefore, for each subject the SDI was calculated by summing up the SQ grade for each of the 13 vertebrae from T4 to L4 $(\mathrm{SDI}=\mathrm{SQT} 4+\ldots+\mathrm{SQT12}+\mathrm{SQL} 1+\ldots+\mathrm{SQL} 4)$ [25].
Statistical analysis

Overall characteristics of the sample study were described by proportion or median and interquartile range (IQR), as continuous variables were not normally distributed (Kolmogorov-Smirnov test). The Wilcoxon rank-sum test or Kruskall-Wallis test were used to compare the median values, while categorical variables were assessed with the chisquare test or Fisher's exact test, as appropriate. A twotailed $p<0.05$ was considered statistically significant.

To examine the association between the type of hip fracture and the possible predictors included in the standardized interview, an exploratory multivariable logistic regression analyses with SDI as measure of vertebral fracture status was run on the Break data, while controlling for age. The backward stepping strategy was undertaken to determine the best model, which involved variables elimination in a hierarchical manner. The same model was also used with the variable previous vertebral fracture instead of SDI. All analyses were performed with SPSS for Windows, version 16.0 (SPSS, Inc., Chicago, IL, USA).

\section{Results}

Of the 1,249 eligible women with hip fracture a complete Xray evaluation of thoracic and lumbar spine was available for 727 patients, but 38 were discharged for inadequate Xray quality. Therefore, the analysis was carried out on the remaining 689 patients. Of these 689 elderly women, 312 did not present any fractures, whereas $377(=54.7 \%)$ presented one or more vertebral fractures; of them, 95 $(=13.7 \%)$ had at least one severe vertebral fracture. The prevalence of vertebral fractures, by spinal location, is shown in Fig. 1. The distribution of vertebral fractures along the spine showed a peak prevalence at T7 and T8 levels (18.8 and $14.2 \%$, respectively). Another, if lower, peak prevalence was at T12 and L1 levels (11.2 and 8.6\%, respectively). In addition, the distribution of severe vertebral fractures showed a similar pattern.

The demographic, clinical, and lifestyle characteristics of the 689 elderly women with hip fracture by fracture localisation are reported in Table 1.

The proportion of SDI as well as previous vertebral fractures medians were significantly higher in women with trochanteric hip fracture with respect to those with cervical hip fracture, $p=0.017$ and $p=0.001$, respectively (Table 1 ). In addition, the proportion of previous severe vertebral fractures was higher in women with trochanteric than in those with cervical hip fracture, but the difference did not reach the statistical significance. Among women with trochanteric hip fracture, apart from higher proportions of diabetes (24.6 vs $15.6 \%, p=0.005)$ and surgical menopause 
Fig. 1 Prevalence of vertebral fractures in 689 elderly women with hip fractures. Results are presented as the frequency of fracture at each vertebral level

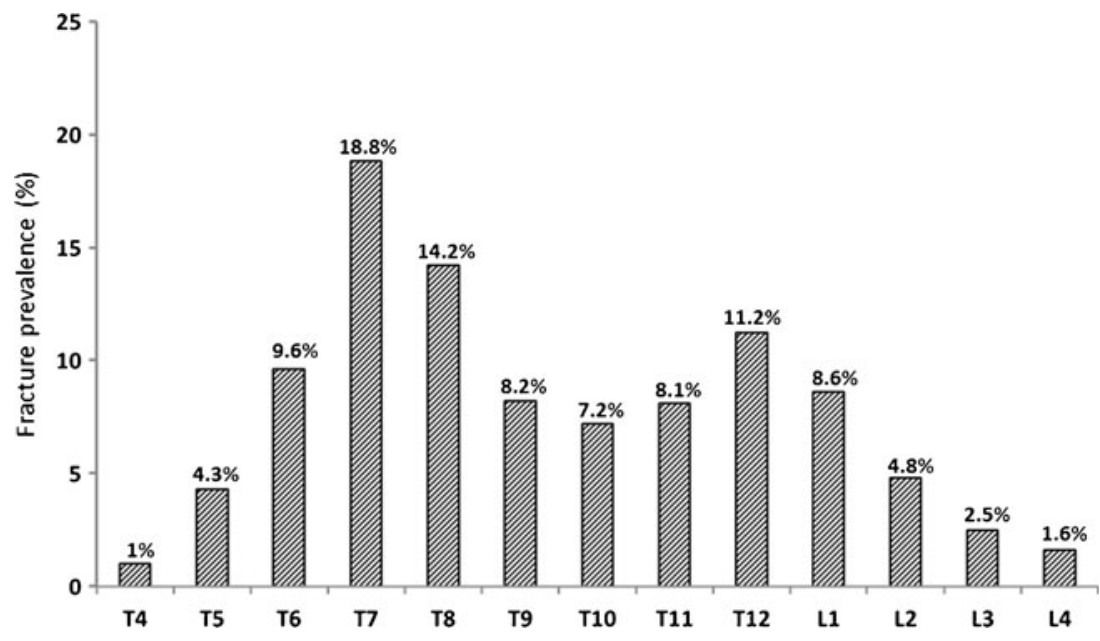

(14.0 vs $8.8 \%, p=0.049)$ and a lower proportion of antidepressant users (13.4 vs $22.1 \%, \mathrm{p}=0.003)$, no statistically significant differences in independent variables were found. Moreover, the women with cervical hip fracture presented a BMI slightly lower with respect to those with trochanteric fracture (Table 1). No differences in prefracture walking ability were observed between the two groups (Table 2). With regard to postsurgery characteristics, significant associations with type of femoral fracture were found for postsurgery complications (32\% trochanteric vs $24.6 \%$ cervical hip fracture, $p=0.041)$ and time to weight permitted $(17.3 \%$ after more than 30 days among trochanteric vs $4.5 \%$ cervical hip fracture, $p<0.001)$. Furthermore, the length of stay in hospital was higher in women with trochanteric than in those with cervical fracture, but the difference did not reach any statistical significance (Table 2).

Table 3 shows the results of the multiple logistic regression analysis on predictors for trochanteric hip fractures. SDI, surgical menopause, family history of fragility fracture, type 2 diabetes mellitus, and use of antihypertensive and antidepressant drugs were independently associated with the risk of trochanteric with respect to the risk of cervical hip fracture.

Women who were in surgical menopause and women with family history of fragility fracture were more likely to have a trochanteric hip fracture (vs cervical hip fracture). Furthermore, the presence of diabetes was associated with an increased risk of having trochanteric hip fracture. Instead, women who used antihypertensive drugs and women who used antidepressant drugs were less likely to have trochanteric than cervical hip fracture. The fully adjusted odds ratio of trochanteric hip fracture for an increase in SDI score of one-unit was $1.10(95 \% \mathrm{CI}$, 1.3-1.16). Therefore, being the regression coefficient for SDI $b=0.088$, the adjusted odds ratio of trochanteric hip fracture was $\mathrm{OR}=1.19$ for an increase in SDI score of two units and $\mathrm{OR}=1.42$ for an increase of four units.

Despite the information provided by SDI being potentially more comprehensive than simple dichotomization of patients into fracture or nonfracture categories, we evaluated the same model with the variable previous vertebral fracture, as directly measurable, instead of SDI. Similar results were found with the same predictors being selected by the stepwise method obtaining $\mathrm{OR}=1.42(95 \% \mathrm{CI}, 1.02-1.95)$ for previous vertebral fracture.

The demographic and clinical characteristics of patients grouped on the basis of SDI values are reported in Table 4. As expected the patients with an elevated SDI were older and shorter with respect to those without prevalent vertebral fractures $(\mathrm{SDI}=0)$. Moreover, a higher SDI was associated with a higher percentage of postsurgery complications ( $p=$ $0.05)$ and slower recovery $(p<0.05)$.

\section{Discussion}

This study, carried out on a large cohort of elderly women with hip fracture, shows that the presence and, above all, the burden of prevalent vertebral fractures are more strictly associated with the trochanteric rather than the cervical localisation of hip fracture. Moreover, this study reveals that elevated values of SDI negatively influence functional outcomes in women with hip fracture.

In this study, $54.7 \%$ of women with hip fracture presented vertebral fractures; however, this high prevalence is lower with respect to other similar studies carrying out spinal radiography in women with hip fracture, which reported vertebral fracture prevalence ranging from 65 to $75 \%[10,27,28]$. On the contrary, the study by Tosteson et al. [29] reported a slightly lower prevalence, but in this latter study, spinal fracture prevalence was derived from anamnesis and clinical records only. However, the prevalence of vertebral fractures in our population is markedly higher than in populations of similar age without hip fracture [27, 30]. Approximately $25 \%$ of our hip fracture patients presented at least one vertebral fracture of severe grade. Although the majority of previous studies of a similar nature did not separately consider the severity grade of vertebral fractures, 
Table 1 Distribution of demographic, clinical and lifestyle characteristics of 689 elderly women with hip fractures by hip fracture localization

\begin{tabular}{|c|c|c|c|c|}
\hline Characteristics & & $\begin{array}{l}\text { Trochanteric fx } \\
\mathrm{n}: 382\end{array}$ & $\begin{array}{l}\text { Cervical fx } \\
\mathrm{n}: 307\end{array}$ & $\begin{array}{l}\mathrm{P}- \\
\text { value }\end{array}$ \\
\hline With previous vertebral fractures, $n /$ total $n(\%)^{a}$ & & $225 / 382(58.9)$ & $152 / 307(49.5)$ & 0.017 \\
\hline $\begin{array}{l}\text { With previous severe vertebral fractures, } \mathrm{n} / \text { total } \mathrm{n} \\
(\%)^{\mathrm{a}}\end{array}$ & & $62 / 382(16.2)$ & $33 / 307(10.7)$ & 0.050 \\
\hline SDI, Skeletal Deformity Index, median (IQR) ${ }^{\mathrm{b}}$ & & $2.0(0-3.3)$ & $0(0-2)$ & 0.001 \\
\hline Surgical menopause, $\mathrm{n} /$ total $\mathrm{n}(\%)^{\mathrm{c}}$ & & $53 / 377(55.4)$ & 27/304 (44.6) & 0.042 \\
\hline Age at menopause (yrs), median $(\mathrm{IQR})^{\mathrm{b}}$ & & $48.1(45-52)$ & $50.0(47-52)$ & 0.482 \\
\hline Age (years), median $(\mathrm{IQR})^{\mathrm{b}}$ & & $81.5(77-87)$ & $81.0(75-85)$ & 0.219 \\
\hline Height $(\mathrm{cm})$, median $(\mathrm{IQR})^{\mathrm{b}}$ & & $160(155-165)$ & $160(155-165)$ & 0.521 \\
\hline BMI (Kg/m2), median(IQR) ${ }^{\mathrm{b}}$ & & $24.5(22.4-27.3)$ & $24.0(22-26.3)$ & 0.015 \\
\hline Smoking, $\mathrm{n} /$ total $\mathrm{n}(\%)^{\mathrm{a}}$ & & $9 / 379(2.4)$ & $16 / 307(5.2)$ & 0.077 \\
\hline Alcohol consumption, $\mathrm{n} /$ total $\mathrm{n}(\%)^{\mathrm{a}}$ & & $24 / 381(6.3)$ & $21 / 306(6.9)$ & 0.887 \\
\hline Wine consumption, $\mathrm{n} /$ total $\mathrm{n}(\%)^{\mathrm{a}}$ & & $47 / 381(12.3)$ & $38 / 307(12.4)$ & 0.920 \\
\hline Family history of fragility fracture, $n /$ total $n(\%)^{a}$ & & $46 / 379(12.1)$ & 24/304 (7.9) & 0.091 \\
\hline $\begin{array}{l}\text { Patient's history of fracture after the age of } 50 \text { years, } \\
n / \text { total } n(\%)^{\mathrm{a}}\end{array}$ & & $120 / 380(31.6)$ & $88 / 306(28.8)$ & 0.474 \\
\hline \multirow[t]{9}{*}{ Comorbidities } & $\begin{array}{l}\text { - Gastrointestinal disorders, } \mathrm{n} / \\
\text { total } \mathrm{n}(\%)^{\mathrm{a}}\end{array}$ & $58 / 382(15.2)$ & $57 / 307(18.6 \%$ & 0.280 \\
\hline & $\begin{array}{l}\text { - Hematologic disorders, } \mathrm{n} / \text { total } \\
\mathrm{n}(\%)^{\mathrm{a}}\end{array}$ & $9 / 382(2.4)$ & $7 / 307(2.3)$ & 0.852 \\
\hline & - Renal disorders, $\mathrm{n} /$ total $\mathrm{n}(\%)^{\mathrm{a}}$ & $24 / 382(6.3)$ & $11 / 307(3.6)$ & 0.153 \\
\hline & $\begin{array}{l}\text { - Endocrine disorders, } \mathrm{n} / \text { total } \mathrm{n} \\
(\%)^{\mathrm{a}}\end{array}$ & 38/382 (9.9) & 25/307 (8.1) & 0.494 \\
\hline & $\begin{array}{l}\text { - Rheumatic disorders, } \mathrm{n} / \text { total } \mathrm{n} \\
(\%)^{\mathrm{a}}\end{array}$ & $13 / 382(3.4)$ & $13 / 307(4.2)$ & 0.713 \\
\hline & - Diabetes, $\mathrm{n} /$ total n $(\%)^{\mathrm{a}}$ & $94 / 382(24.6)$ & 48/307 (15.6) & 0.005 \\
\hline & - BPCO, n/total n $(\%)^{\mathrm{a}}$ & $47 / 382(12.3)$ & 28/307 (9.1) & 0.226 \\
\hline & $\begin{array}{l}\text { - Cerebrovascular diseases, } \mathrm{n} / \\
\text { total } \mathrm{n}(\%)^{\mathrm{a}}\end{array}$ & $16 / 382(4.2)$ & $17 / 307(5.5)$ & 0.519 \\
\hline & $\begin{array}{l}\text { - Cardiovascular diseases, } \mathrm{n} / \text { total } \\
\mathrm{n}(\%)^{\mathrm{a}}\end{array}$ & $120 / 382(31.4)$ & $96 / 307(31.3)$ & 0.968 \\
\hline \multirow[t]{11}{*}{ Medications } & - Antiosteoporotic, $\mathrm{n} /$ total n $(\%)^{\mathrm{a}}$ & $94 / 379(24.8)$ & $69 / 307(22.5)$ & 0.534 \\
\hline & - FANS, n/total n $(\%)^{\mathrm{a}}$ & $25 / 382(6.5)$ & $21 / 307(6.8)$ & 0.880 \\
\hline & - Statins, $\mathrm{n} /$ total n $(\%)^{\mathrm{a}}$ & $32 / 382(8.4)$ & 28/307 (9.1) & 0.835 \\
\hline & $\begin{array}{l}\text { - Antihypertensives, } \mathrm{n} / \text { total } \mathrm{n} \\
(\%)^{\mathrm{a}}\end{array}$ & 267/382 (69.9) & 228/307 (74.3) & 0.236 \\
\hline & - Antiarrhythmics, $\mathrm{n} /$ total n $(\%)^{\mathrm{a}}$ & $80 / 382(20.9)$ & $50 / 307(16.3)$ & 0.146 \\
\hline & - Antiplatelets, n/total n (\%) ${ }^{\mathrm{a}}$ & $94 / 382(24.6)$ & $63 / 307(20.5)$ & 0.113 \\
\hline & $\begin{array}{l}\text { - Ansiolitics/Hypnotics, } \mathrm{n} / \text { total } \mathrm{n} \\
(\%)^{\mathrm{a}}\end{array}$ & $72 / 382(18.8)$ & $74 / 307(24.1)$ & 0.835 \\
\hline & - Antidepressants, $\mathrm{n} /$ total $\mathrm{n}(\%)^{\mathrm{a}}$ & $51 / 382(13.4)$ & $68 / 307(22.1)$ & 0.003 \\
\hline & - Anticoagulants, $\mathrm{n} /$ total $\mathrm{n}(\%)^{\mathrm{a}}$ & $120 / 382(31.4)$ & $83 / 307(27.0)$ & 0.242 \\
\hline & $\begin{array}{l}\text { - Thyroid hormones, } \mathrm{n} / \text { total } \mathrm{n} \\
(\%)^{\mathrm{a}}\end{array}$ & $14 / 382(3.7)$ & 7/307 (2.3) & 0.407 \\
\hline & - Glucocorticoids, $\mathrm{n} /$ total $\mathrm{n}(\%)^{\mathrm{a}}$ & $19 / 382(5.0)$ & 15/307 (4.9) & 0.901 \\
\hline
\end{tabular}

a Dichotomous variable, reference NO (chi-square Yates corrected test)

${ }^{\mathrm{b}}$ Mann-Witneytest

${ }^{\mathrm{c}}$ categorical variable (reference category, spontaneous)

our findings seem to be in agreement with a recent study carried out on a small cohort of Finnish women with hip fracture [12]. The distribution pattern of fractures along the spine was similar to that of previous studies, but in our study, the percentage of fractures at thoracic level was higher than that reported in other studies which, however, were carried out on elderly women of a lower mean age [31]. 
Table 2 Pre- and postsurgery characteristics of 689 elderly women with hip fracture by hip fracture localization
${ }^{\mathrm{a}}$ Dichotomous variable (reference category: $N O$ )

${ }^{\mathrm{b}}$ Ordinal variable (chi-square for linear trend test)

\begin{tabular}{lccc}
\hline Characteristics & Trochanteric fracture & Cervical fracture & $p$ value \\
\hline Prefracture ambulatory capacity, $n /$ total $n(\%)$ & & & 0.167 \\
$\quad$ Inability to walk & $10 / 379(2.6)$ & $7 / 305(2.3)$ & \\
Dipendent walking & $174 / 379(45.9)$ & $119 / 305(39.0)$ & \\
Indipendent walking & $195 / 379(51.5)$ & $179 / 305(58.7)$ & \\
With post-surgey complications, $n /$ total $n(\%)^{\mathrm{a}}$ & $120 / 375(32.0)$ & $75 / 305(24.6)$ & 0.041 \\
Permetted load, $n /$ total $n(\%)^{\mathrm{b}}$ & & & $<0.001$ \\
$<10$ days & $150 / 370(40.5)$ & $207 / 292(70.9)$ & \\
$10-30$ days & $156 / 370(42.2)$ & $72 / 292(24.7)$ & \\
$31-40$ days & $25 / 370(6.8)$ & $4 / 292(1.4)$ & \\
$>40$ days & $39 / 370(10.5)$ & $9 / 292(3.1)$ & \\
\hline
\end{tabular}

The results of our study seem to support the hypothesis that the two main categories of hip fracture, cervical and trochanteric, differ in pathophysiological mechanisms and consequently in predisposing factors [14]. In particular, the more strict association of vertebral fractures with extracapsular hip fracture may be explained by the fact that the trochanteric structure is rather similar to that of vertebrae, involving 60 to $90 \%$ of trabecular bone.

Baudoin et al. [32] demonstrated that the ratio of cervical to trochanteric fractures is above unity under the age of 60 , but thereafter progressively decreases due to the rapid increase in trochanteric fractures with aging. Moreover, Mautalen et al. [16] in a review of literature demonstrated that previous vertebral fractures had been found twice as frequently in patients with trochanteric fracture compared with those with cervical fracture. More recently, a study carried out in the EPIDOS population

Table 3 Results of backward stepwise regression models: factors associated with trochanteric hip fractures

\begin{tabular}{lcc}
\hline Independent variables $^{\mathrm{c}}$ & \multicolumn{2}{l}{ Trochanteric hip fracture $^{\mathrm{a}}$} \\
\cline { 2 - 3 } & OR & $95 \% \mathrm{CI}$ \\
\hline SDI & 1.10 & $1.03-1.16$ \\
Age & 1.03 & $1.01-1.05$ \\
Surgical menopause & 1.71 & $1.03-2.85$ \\
Family history of fragility fracture & 1.96 & $1.13-3.40$ \\
Antihypertensive drugs & 0.64 & $0.45-0.93$ \\
Antidepressant drugs & 0.53 & $0.35-0.81$ \\
Diabetes & 1.88 & $1.25-2.84$ \\
\hline
\end{tabular}

Predictors were listed in decreasing order according to the respective standardized values ( $p$ coefficient) to indicate the decreasing relative contribution to the model

${ }^{a}$ Reference category: cervical hip fracture

${ }^{\mathrm{b}}$ Reference category: spontaneous

${ }^{\mathrm{c}}$ Whole set of variables included into the models: SDI, age, BMI, high, menopause type, smoking, alcohol consumption, history of fracture after the age of 50 years, family history of fragility fracture, prefracture walking ability, comorbidities, and concomitant therapies reported that all BMD measures as well as quantitative ultrasound measures were stronger predictors of trochanteric rather than cervical fractures [17]. Moreover, Gnudi et al. found that trochanteric BMD was a better predictor of trochanteric fractures than of cervical fractures, whereas proximal femur geometry played a significant role only in the prediction of cervical fracture [33]. More recently Sosa has reported that the prevalence of vertebral fractures was significantly higher in patients with non cervical than in those with cervical fractures [27]. On the contrary, other studies did not find any significant correlations between hip fracture localisation and prevalence of vertebral fractures [10]. In addition, Fox et al. [34] found that maternal history of hip fracture, body composition, and history of fracture after the age of 50 years were predictors of hip fracture but not of any one of the two types.

One of the major findings of our study is the strict association of trochanteric hip fractures with the burden of prevalent vertebral fractures. In fact, there is a growing conviction that it may be more relevant, for an adequate assessment of future fracture risk, to assess all vertebral fractures rather than to consider the spine as a binary parameter (fracture Yes/No) as in FRAX. The SDI is a summary measure of vertebral fracture status incorporating both the number and the severity of vertebral fractures [25]. Two studies have suggested that SDI may be an accurate tool for vertebral fracture prediction and that baseline SDI was predictive of the 3-year incidence of subsequent vertebral fracture regardless of BMD $[25,26]$.

It has also been reported that the risks of hip and any nonvertebral fractures increase with an increasing SDI [35]. This is in line with histological data showing that microarchitectural deterioration of bone is proportionally worse in women with increasing SDI values, suggesting SDI as a surrogate marker of bone fragility [36]. Thus, the evaluation of spine radiographs and the use of SDI may provide useful information for guidance for clinical decision making regarding the need for lifestyle modifications and pharmaceutical interventions [37]. 
Table 4 Selected demographic and clinical characteristics of 689 elderly women with hip fracture grouped by Spinal Deformity Index (SDI)

\begin{tabular}{|c|c|c|c|c|c|}
\hline Characteristics & $\mathrm{SDI}=0(n=312)$ & $\begin{array}{l}\text { SDI }=1-2 \\
(n=169)\end{array}$ & $\begin{array}{l}\mathrm{SDI}=3-4 \\
(n=120)\end{array}$ & $\mathrm{SDI}>4(n=88)$ & $p$ value \\
\hline Age (years), median (IQR) ${ }^{\mathrm{a}}$ & $81.0(75-86)$ & $81.0(76-85)$ & $82.0(75-86)$ & $83.0(77-87)$ & 0.31 \\
\hline Height $(\mathrm{cm})$, median $(\mathrm{IQR})^{\mathrm{a}}$ & $161.2(155-165)$ & $160.0(155-165)$ & $160.0(156-165)$ & $159.0(150-164)$ & 0.10 \\
\hline BMI $\left(\mathrm{kg} / \mathrm{rn}^{2}\right)$, median $(\mathrm{IQR})^{\mathrm{a}}$ & $24.2(22-27)$ & $24.2(22-27)$ & $25.0(23-27)$ & $24.4(22-27)$ & 0.76 \\
\hline Age at menopause (years), median (IQR) ${ }^{\mathrm{b}}$ & $50.0(46-52)$ & $50.0(47-52)$ & $50.0(46-51)$ & $50.0(45-51)$ & 0.24 \\
\hline Family history of fragility fracture, $n /$ total $n(\%)^{\mathrm{b}}$ & $38 / 309(12.3)$ & $13 / 166(7.8)$ & $9 / 120(7.5)$ & $10 / 88(11.4)$ & 0.47 \\
\hline History of fracture after 50 years, $n /$ total $n(\%)^{\mathrm{b}}$ & $86 / 311(27.7)$ & $46 / 167(27.5)$ & $36 / 120(30.0)$ & $40 / 88(45.5)$ & 0.004 \\
\hline Prefracture ambulatory capacity, $n /$ total $n(\%)^{\mathrm{b}}$ & & & & & 0.12 \\
\hline Inability to walk & $10 / 312(3.2)$ & 2/169 (1.2) & $3 / 120(2.5)$ & $5 / 88(5.7)$ & \\
\hline Dependent walking & $129 / 312(41.3)$ & $69 / 169(40.8)$ & $56 / 120(46.7)$ & $40 / 88(45.4)$ & \\
\hline Independent walking & $173 / 312(55.5)$ & $98 / 169(58.0)$ & $61 / 120(50.8)$ & 43/88 (48.9) & \\
\hline With postsurgery complications, $n /$ total $n(\%)^{\mathrm{a}}$ & $85 / 307(27.7)$ & $42 / 167(25.1)$ & $35 / 120(29.2)$ & $33 / 86(37.5)$ & 0.05 \\
\hline Permetted load, $n /$ total $n(\%)$ & & & & & 0.045 \\
\hline$<10$ days & $166 / 299(55.5)$ & $91 / 163(55.8)$ & $62 / 116(53.4)$ & $38 / 84(45.2)$ & \\
\hline 10-30 days & $102 / 299(34.1)$ & $52 / 163(31.9)$ & 44/116 (37.9) & $30 / 84(35.7)$ & \\
\hline $31-40$ days & $15 / 299(5.0)$ & $7 / 163(4.3)$ & 2/116 (1.7) & $5 / 84(6.0)$ & \\
\hline$>40$ days & $16 / 299(5.4)$ & $13 / 163(8.0)$ & $8 / 116(6.9)$ & $11 / 84(12.5)$ & \\
\hline
\end{tabular}

${ }^{\text {a }}$ Kruskall-WaIIis test

${ }^{\mathrm{b}}$ Chi-square test

Since vertebral fractures occur at an earlier age than hip fracture, the early identification and targeting interventions for such individuals may help to reduce the burden of morbidity due to hip fracture later in life. At present, the literature data do not permit any conclusions as to whether present therapeutic strategies may have any different fracture reduction effect for cervical and trochanteric hip fractures. Concerning this point, one might speculate that osteoporosis medications may be able to reduce trochanteric hip fracture through a similar mechanism as for that of vertebral fractures by increasing (trochanteric) BMD, while the effect on cervical fracture risk may be more limited [14]. The fact that, in our population, several clinical risk factors for osteoporotic fracture, such as surgical menopause and family history of fracture, are more strictly associated with trochanteric hip fracture seems to confirm the hypothesis that this latter may represent the hip fracture type more closely connected to bone fragility.

Our data are consistent with previous observations that there are no differences between the two hip fracture types with regard to comorbidity burden [19, 20]. However, in this study, we documented a statistically significant difference between the two hip fracture groups in the prevalence of type 2 diabetes (higher among elderly women with trochanteric fracture). This finding, although not observed in previous studies, which have taken comorbidities into consideration $[18,19]$, may be explained by the fact that type 2 diabetes is associated with an increased bone fragility, leading to an increased risk of hip fractures especially at trochanteric level, which have been hypothesized as being more typical of conditions of fragility [16, 38].

The concomitant therapies taken by the patients when hip fracture occurred do not present any significant associations with either of the two types of hip fracture, with the exception of antihypertensive and antidepressant drugs, which appear to be inversely associated with trochanteric hip fracture. At present, there is no literature data that are able to confirm this finding; we can only hypothesize that these drugs may influence the type and frequency of falls. Similarly, Fisher et al. [20] reported a greater association between cervical hip fracture and the presence of Parkinson's disease, which is considered a cause of frequent falls.

In the present study, short-term functional recovery was slower in elderly women with trochanteric fractures than in those with cervical fracture. However, this difference should be interpreted with caution, as it is likely to reflect differences in surgical procedures and/or rehabilitative strategies [19]. In fact, most previous studies reported similar functional outcomes in both fracture types at 6 months and at 1 year [19]. Moreover, our data seem to be in agreement with the study by Di Monaco et al. [28] who reported that SDI was negatively associated with functional outcomes in elderly women with hip fracture admitted consecutively to a rehabilitation hospital. It is possible that the positive association between functional outcomes and levels of SDI could be due to an increased probability of trochanteric hip fracture in patients with an elevated SDI, since trochanteric hip fractures are characterized by a slower recovery. 
Our study has some limitations: firstly, the crosssectional nature of the study does not allow the establishing of any causality relationships between the parameters; secondly, the lack of a comparator group of patients without hip fracture does not permit the determinations as whether the findings of hip fracture patients are different from those without hip fracture; thirdly, the fact that no information is available regarding vitamin D status, bone turnover markers, and BMD; fourthly, the fact that the classification of hip fractures was carried out at each individual center; finally, the fact that, in our patients, fall dynamics were not assessed. Nevertheless, our study presents several strong points: firstly, the large and homogeneous sample size of elderly women with hip fracture; secondly, the fact that the presence and severity of vertebral fractures was assessed by a centralized morphometric analysis on spine radiographs.

In conclusion, our study suggests that the burden of prevalent vertebral fractures is more strictly associated with the trochanteric than the cervical localisation of hip fracture and that elevated values of SDI negatively influence short term functional outcomes in women with hip fracture. This finding supports the opinion that SDI should be incorporated along with other known factors for fragility fracture risk assessment.

Recognition of the differing physiopathological features of cervical and trochanteric fracture needs to be recognized in clinical fracture risk assessment and may also open up improved strategies for prevention and therapy.

Acknowledgment This study was supported by a research grant from Nycomed Italia.

The Break Study Group: M. Rondena (Legnano-MI), S. Bernasconi (Legnano-MI), G. Miele (Milano), F. Cosignani (Sesto San GiovanniMI), B.N.G. Conti (Sesto San Giovanni-MI), I. Santi (Milano), G. Arioli (Mantova), M. Manfredini (Mantova), G. Gandolini (Milano), M. Invernizzi (Novara), C. Cisari (Novara), M. Rossini (Verona), G. Letizia Mauro (Palermo), G. Sanguedolce (Palermo), C. Venza (Palermo), R. Nuti (Siena), P. Nalin (Padova), M.G. Veloce (Padova), S. Flamini (L'Aquila), R. Laforgia (Matera), G. Iolascon (Napoli), C. Angrisani (Caserta), F. Sdaganelli (Taranto), M. Leone (Rutiogliano-BA), D. Topini ( $\operatorname{san}$ Martino al Cimino-VT), M. Cavallaio (Torino), and L. Aulisa (Roma).

\section{Conflicts of interest None.}

\section{References}

1. NIH Consensus Development Panel on Osteoporosis Prevention, Diagnosis and Therapy (2001) Osteoporosis prevention, diagnosis and therapy. JAMA 285:785-795

2. Cooper C, Atkinson EJ, O'Fallon WM, Melton LJ 3rd (1992) Incidence of clinically diagnosed vertebral fractures: a population-based study in Rochester, Minnesota, 1985-1989. J Bone Miner Res 7:221-227

3. Gullberg B, Johnell O, Kanis JA (1997) World-wide projections for hip fracture. Osteoporos Int 7:407-413
4. Cummings SR, Melton LJ (2002) Epidemiology and outcomes of osteoporotic fractures. Lancet 359:1761-1767

5. Klotzbuecher CM, Ross PD, Landsman PB, Abbott TA 3rd, Berger M (2000) Patients with prior fractures have an increased risk of future fractures: a summary of the literature and statistical synthesis. J Bone Miner Res 15:721-739

6. Black DM, Arden NK, Palermo L, Pearson J, Cummings SR (1999) Prevalent vertebral deformities predict hip fractures and new vertebral deformities but not wrist fractures Study of Osteoporotic Fractures Research Group. J Bone Miner Res 14:821-828

7. Ismail AA, Cockerill W, Cooper C, Finn JD, Abendroth K, Parisi $\mathrm{G}$ et al (2001) Prevalent vertebral deformity predicts incident hip though not distal forearm fracture: results from the European Prospective Osteoporosis Study. Osteoporos Int 12:85-90

8. Chen JS, Cameron ID, Simpson JM, Seibel MJ, March LM, Cumming RG et al (2011) Low-trauma fractures indicate increased risk of hip fracture in frail older people. J Bone Miner Res 26:428-433

9. Johnell O, Oden A, Caulin F, Kanis JA (2001) Acute and longterm increase in fracture risk after hospitalization for vertebral fracture. Osteoporos Int 12:207-214

10. Hasserius R, Johnell O, Nilsson BE, Thorngren KG, Jonsson K, Mellström D et al (2003) Hip fracture patients have more vertebral deformities than subjects in population-based studies. Bone $32: 180-184$

11. Schousboe JT, Fink HA, Lui LY, Taylor BC, Ensrud KE (2006) Association between prior non-spine non-hip fractures or prevalent radiographic vertebral deformities known to be at least 10 years old and incident hip fracture. J Bone Miner Res 21:1557-1564

12. Puisto V, Heliövaara M, Impivaara O, Jalanko T, Kröger H, Knekt $P$ et al (2011) Severity of vertebral fracture and risk of hip fracture: a nested case-control study. Osteoporos Int 22:63-68

13. Ferrar L, Roux C, Reid DM, Felsenberg D, Glüer CC, Eastell R (2012) Prevalence of non-fracture short vertebral height is similar in premenopausal and postmenopausal women: the osteoporosis and ultrasound study. Osteoporos Int 23:1035-1040

14. Pulkkinen P, Glüer CC, Jämsä T (2011) Investigation of differences between hip fracture types: a worthy strategy for improved risk assessment and fracture prevention. Bone 49:600-604

15. Kotowicz MA, Melton LJ 3rd, Cooper C, Atkinson EJ, O'Fallon WM, Riggs BL (1994) Risk of hip fracture in women with vertebral fracture. J Bone Miner Res 9:599-605

16. Mautalen CA, Vega EM, Einhorn TA (1996) Are the aetiologies of cervical and trochanteric hip fractures different? Bone 18:133S$137 \mathrm{~S}$

17. Schott AM, Hans D, Duboeuf F, Dargent-Molina P, Hajri T, Bréart G, Meunier PJ, EPIDOS Study Group (2005) Quantitative ultrasound parameters as well as bone mineral density are better predictors of trochanteric than cervical hip fractures in elderly women. Results from the EPIDOS study. Bone 37:858-863

18. Jokinen H, Pulkkinen P, Korpelainen J, Heikkinen J, KeinänenKiukaanniemi S, Jämsä T, Korpelainen R (2010) Risk factors for cervical and trochanteric hip fractures in elderly women: a population-based 10-year follow-up study. Calcif Tissue Int 87:44-51

19. Haentjens P, Autier P, Barette M, Venken K, Vanderschueren D, Boonen S, Hip Fracture Study Group (2007) Survival and functional outcome according to hip fracture type: a one-year prospective cohort study in elderly women with an intertrochanteric or femoral neck fracture. Bone 41:958-964

20. Fisher A, Srikusalanukul W, Davis M, Smith P (2010) Hip fracture type: important role of parathyroid hormone $(\mathrm{PTH})$ response to hypovitaminosis D. Bone 47:400-407

21. Stewart A, Porter RW, Primrose WR, Walker LG, Reid DM (1999) Cervical and trochanteric hip fractures: bone mass and other parameters. Clin Rheumatol 18:201-206 
22. Partanen J, Heikkinen J, Jämsä T, Jalovaara P (2002) Characteristics of lifetime factors, bone metabolism, and bone mineral density in patients with hip fracture. J Bone Miner Metab 20:367-375

23. Maggi S, Siviero P, Gonnelli S, Caffarelli C, Gandolini G, Cisari C, Break Study Group et al (2011) The burden of previous fractures in hip fracture patients. The Break Study. Aging Clin Exp Res 23:183-186

24. Genant HK, Wu CY, van Kuijk C, Nevitt MC (1993) Vertebral fracture assessment using a semiquantitative technique. J Bone Miner Res 8:1137-1148

25. Crans GG, Genant HK, Krege JH (2005) Prognostic utility of a semiquantitative spinal deformity index. Bone 37:175-179

26. Kerkeni S, Kolta S, Fechtenbaum J, Roux C (2009) Spinal deformity index (SDI) is a good predictor of incident vertebral fractures. Osteoporos Int 20:1547-1552

27. Sosa HM, Saavedra SP, grupo de trabajo en osteoporosis de la Sociedad Española de Medicina Interna (SEMI) (2007) Prevalence of vertebral fractures in hip fracture patients. Rev Clin Esp 207:464-468

28. Di Monaco M, Vallero F, Di Monaco R, Franza G, Tappero R (2011) The burden of prevalent vertebral fractures is negatively associated with functional outcome in women with hip fracture. Am J Phys Med Rehabil 90:1-7

29. Tosteson AN, Gabriel SE, Grove MR, Moncur MM, Kneeland TS, Melton LJ 3rd (2001) Impact of hip and vertebral fractures on quality-adjusted life years. Osteoporos Int 12:1042-1049

30. Jackson SA, Tenenhouse A, Robertson L (2000) Vertebral fracture definition from population-based data: preliminary results from the Canadian Multicenter Osteoporosis Study (CaMos). Osteoporos Int 11:680-687
31. Nevitt MC, Ross PD, Palermo L, Musliner T, Genant HK, Thompson DE (1999) Association of prevalent vertebral fractures, bone density, and alendronate treatment with incident vertebral fractures: effect of number and spinal location of fractures. The Fracture Intervention Trial Research Group. Bone 25:613-619

32. Baudoin C, Fardellone P, Sebert JL (1993) Effect of sex and age on the ratio of cervical to trochanteric hip fracture. A meta-analysis of 16 reports on 36,451 cases. Acta Orthop Scand 64:647-653

33. Gnudi S, Ripamonti C, Lisi L, Fini M, Giardino R, Giavaresi G (2002) Proximal femur geometry to detect and distinguish femoral neck fractures from trochanteric fractures in postmenopausal women. Osteoporos Int 13:69-73

34. Fox KM, Cummings SR, Williams E, Stone K, Study of Osteoporotic Fractures (2000) Femoral neck and intertrochanteric fractures have different risk factors: a prospective study. Osteoporos Int 11:1018-1023

35. Delmas PD, Genant HK, Crans GG, Stock JL, Wong M, Siris E, Adachi JD (2003) Severity of prevalent vertebral fractures and the risk of subsequent vertebral and nonvertebral fractures: results from the MORE trial. Bone 33:522-532

36. Genant HK, Delmas PD, Chen P, Jiang Y, Eriksen EF, Dalsky GP et al (2007) Severity of vertebral fracture reflects deterioration of bone microarchitecture. Osteoporos Int 18:69-76

37. Netelenbos JC, Lems WF, Geusens PP, Verhaar HJ, Boermans AJ et al (2009) Spine radiographs to improve the identification of women at high risk for fractures. Osteoporos Int 20:1347-1352

38. Schwartz AV, Sellmeyer DE, Ensrud KE, Cauley JA, Tabor HK, Schreiner PJ, Jamal SA, Black DM, Cummings SR, Study of Osteoporotic Features Research Group (2001) Older women with diabetes have an increased risk of fracture: a prospective study. J Clin Endocrinol Metab 86:32-38 